\title{
Influence of sodium chloride on the colloidal and rennet coagulation properties of concentrated casein micelle suspensions
}

\author{
Z. Zhao and M. Corredig ${ }^{1}$ \\ Department of Food Science, University of Guelph, Guelph, Ontario, N1G 2W1, Canada
}

\begin{abstract}
The research investigated the influence of $\mathrm{NaCl}$ on the colloidal and rennet coagulation properties of concentrated milk. Milk was concentrated to $1 \times, 3 \times$, and $5 \times$ using ultrafiltration. Rennet gelation was followed by rheology and diffusing wave spectroscopy. Soluble protein, total and diffusible calcium and phosphate, size, and zeta potential were also measured as a function of concentration history. In the presence of 300 $\mathrm{m} M \mathrm{NaCl}$, colloidal calcium phosphate solubilized and $\mathrm{pH}$ and the negative charge on the surface of casein micelles decreased. Increasing the volume fraction caused the formation of stiffer gels for both samples with or without $\mathrm{NaCl}$. The addition of $\mathrm{NaCl}$ caused a significant increase in the bulk viscosity of the milk concentrated $5 \times$ and a decrease in turbidity. The concentration had no effect on the gelation time of control samples, nor on the kinetics of caseinomacropeptide release. On the other hand, rennet gelation was retarded by the addition of $\mathrm{NaCl}$, and the gels showed lower elastic moduli compared with those obtained with control milk.
\end{abstract}

Key words: casein micelles, sodium chloride, concentrated milk, rennet gelation

\section{INTRODUCTION}

Skim milk is a dispersion of proteins, minerals, and lactose. The major proteins in milk are caseins, which are present in the form of casein micelles. Casein micelles play an important role in the processing functionality of milk (Dalgleish, 2011; Dalgleish and Corredig, 2012). The structure of casein micelle has attracted the attention of scientists, and many models have been proposed to elucidate the structure of casein micelles over the past 50 yr (Holt, 1992, 1998; Horne, 2006; Dalgleish and Corredig, 2012). Colloidal calcium phosphate nanoclusters, with an average radius of 2.3 $\mathrm{nm}$, are present in the inner core of the casein micelles

Received November 10, 2015.

Accepted January 31, 2016.

${ }^{1}$ Corresponding author: milena.corredig@uoguelph.ca and are surrounded by phosphorylated caseins $\left(\alpha_{S^{-}}\right.$ and $\beta$-CN; Holt, 1998, 2004). $\kappa$-Casein molecules are located on the surface of the casein micelle, providing a polyelectrolyte brush of great importance to the colloidal stability of these protein particles (De Kruif and Zhulina, 1996).

The structure of casein micelles is affected by changes of environment, such as $\mathrm{pH}$, temperature, and the presence of other minerals (Grufferty and Fox, 1985; Le Graët and Gaucheron, 1999; Carr et al., 2002; Huppertz and Fox, 2006). It has been reported that the addition of sodium chloride $(\mathrm{NaCl})$ causes the solubilization of colloidal calcium phosphate, increases dissociation of caseins, and improves the solubility of milk concentrates (Mao et al., 2012); however, it may influence the processing functionality of casein micelles (Famelart et al., 1999; Gaucheron et al., 2000). Furthermore, the addition of $\mathrm{NaCl}$ decreases milk $\mathrm{pH}$ (Huppertz and Fox, 2006) and increases the hydration of casein micelle (Van Hooydonk et al., 1986).

Recent research demonstrated that when $\mathrm{NaCl}$ is added to $1 \times$ and $2 \times$ concentrated milk, there is dissolution of the colloidal calcium phosphate and release of caseins, with consequent changes of viscosity and turbidity (Zhao and Corredig, 2014). However, few studies conducted on the influence of $\mathrm{NaCl}$ on concentrated milk can be found, and further research is needed to better understand the effect of charge shielding and, in particular, the addition of $\mathrm{NaCl}$ on the processing properties of casein micelles.

Rennet coagulation is a critical processing step in cheesemaking. The rennet gelation involves 2 overlapping stages. The primary stage is the cleavage of $\kappa-\mathrm{CN}$; once enough $\kappa$-CN (about 85-90\%) is cleaved, the second stage, aggregation of the casein micelles, occurs with the formation of a gel network (Lucey, 2002; Liu et al., 2014). Concentration of skim milk using ultrafiltration increases the proteins and colloidal minerals in the retentate and decreases the average distance between casein micelles (Sandra et al., 2011). Previous researchers found that concentrated milk has a longer coagulation time and higher gel firming rate than nonconcentrated milk (Dalgleish, 1980; Waungana et al., 
1999). However, recent research (Sandra et al., 2011) showed that concentration has no significant effect on the release of caseinomacropeptide (CMP) and coagulation time when the same amount of rennet is added to milk. Addition of $\mathrm{NaCl}$ was reported to increase the coagulation time of milk (Sbodio et al., 2006). It is still unknown how $\mathrm{NaCl}$ will influence the rennet coagulation of concentrated milk.

This research aims to better understand the influence of addition of $\mathrm{NaCl}$ before concentration on the structure of casein micelles and on the rennet gelation behavior of the concentrated milk. The concentration $(1 \times, 3 \times$, and $5 \times)$ was achieved by ultrafiltration based on the volume fraction. In our study, the rennet gelation process was followed by rheology and diffusing wave spectroscopy (DWS). Before rennet gelation, the changes in the physicochemical properties of concentrated milk were characterized by measuring total and soluble protein, total and diffusible calcium and phosphate, hydrodynamic size, zeta potential, and light scattering properties using DWS.

\section{MATERIALS AND METHODS}

\section{Preparation of Concentrated Milk}

Skim milk was obtained from a local dairy company (Crown Dairy, Guelph, ON, Canada). A total of $0.01 \%$ sodium azide was added immediately to prevent the bacterial growth. Sodium chloride $(300 \mathrm{mmol} / \mathrm{L})$ was added to milk and stirred for $15 \mathrm{~min}$ at room temperature. This concentration was chosen based on prior results, which showed a significant change in the size of the casein micelles and turbidity parameter of milk (Zhao and Corredig, 2014). All the samples were then equilibrated overnight in the refrigerator. After equilibration, aliquots of samples $(1 \mathrm{~L})$ were concentrated to different concentrations $(1 \times, 3 \times$, and $5 \times)$ using an ultrafiltration cartridge (10-kDa Millipore CDUF001LG, Fisher Scientific, Mississauga, ON, Canada) based on the volume reduction. All permeates were collected.

\section{Determination of Total and Soluble Protein Content}

The total protein was determined directly using a Dumas nitrogen analyzer (FP-528, Leco Inc., Lakeview Avenue, St. Joseph, MI). The protein concentration was calculated using 6.38 as conversion factor.

The soluble protein was defined as the fraction that did not sediment after ultracentrifugation at 100,000 $\times$ $g$ for $1 \mathrm{~h}$ at $20^{\circ} \mathrm{C}$ (OptimaTM LE-80K ultracentrifuge with rotor type 70.1Ti, Beckman Coulter Canada Inc., Mississauga, Canada). The supernatants were then filtered through the $0.45-\mu \mathrm{m}$ membrane (low protein binding, Fisher Scientific) before analysis.

\section{Determination of Total and Diffusible Calcium and Phosphate}

In this research, the 861 Advanced Compact IC ( $\Omega$ Metrohm ion analysis, Metrohm Ltd., Herisau, Switzerland) was used to measure the total and diffusible calcium and phosphate in milk. The diffusible calcium and phosphate were defined as those present in the supernatant but not combined with the serum proteins. The sample preparation for both total and diffusible calcium and phosphate has been described in our previous research (Zhao and Corredig, 2014).

The calcium was determined using nonsuppressed ion chromatography (Rahimi-Yazdi et al., 2010). On the other hand, a $\mathrm{CO}_{2}$ suppressed ion chromatographic method was used to determine the total and diffusible phosphate. An anion exchange column (Metrosep A Supp5-150/4.0, Metrohm) packed with 5- $\mu \mathrm{m}$ polyvinyl alcohol with quaternary ammonium groups was employed. Sodium hydrogen carbonate and sodium carbonate solutions were used to prepare the mobile phase $(1.0 \mathrm{~m} M$ sodium carbonate and $4 \mathrm{~m} M$ sodium hydroxide). Samples were eluted at a flow rate of 0.5 $\mathrm{mL} / \mathrm{min}$.

\section{Addition of Rennet and $\mathrm{k}-\mathrm{CN}$ Hydrolysis}

Before the addition of rennet, milk samples were equilibrated at $30^{\circ} \mathrm{C}$ for at least $20 \mathrm{~min}$. The rennet used was Chymax Ultra (Chr. Hansen, Milwaukee, WI) with average strength of $790( \pm 5 \%)$ international milk clotting units (IMCU) $/ \mathrm{mL}$. The rennet was diluted 100-fold in MilliQ water (Thermo Fisher Scientific, Burlington, Canada) before addition to milk. The diluted rennet was added to milk with a proportion of 4 $\mu \mathrm{L} / \mathrm{mL}$ of milk. The final concentration of rennet in milk was $0.031 \mathrm{IMCU} / \mathrm{mL}$. Milk samples were stirred for $30 \mathrm{~s}$ after rennet addition before further analysis. The gelation process was carried out at $30^{\circ} \mathrm{C}$.

The release of CMP by rennet was monitored using an established method (Lopez-Fandino et al., 1993). Rennet at the concentration defined above was added to the milk sample, which was then immediately divided into 2-mL aliquots in different test tubes. Samples were incubated at $30^{\circ} \mathrm{C}$, and the reaction was stopped at designated times (every $10 \mathrm{~min}$ ) by addition of $4 \mathrm{~mL}$ of $3 \%$ trichloroacetic acid. After overnight storage in refrigerator, the supernatant was collected and then centrifuged at $4,500 \times g$ for $15 \mathrm{~min}$ at $22^{\circ} \mathrm{C}$ (Eppendorf centrifuge, 5415D, Mississauga, Canada). The obtained superna- 
tants were then filtered through using $0.45-\mu \mathrm{m}$ filters (syringe driven filters, Fisher Scientific). The content of CMP was then determined using reverse phase-HPLC. The HPLC was an Ultimate3000 LC (Thermo Scientific, Burlington, ON, Canada) with degasser, pump, auto-sampler, and UV detector (set to $210 \mathrm{~nm}$ ). The sample $(100 \mu \mathrm{L})$ was injected on a column (Pharmacia Biotech $\mu$ RPC C2/C18 ST 4.6/100, Piscataway, NJ, with a Vydac C-4 guard column, Mandel Scientific Co. Inc., Guelph, ON, Canada), and elution was carried out with $0.1 \%$ trifluoroacetic acid (TFA) in water and $0.1 \%$ TFA in $90 \%$ acetonitrile in a nonlinear gradient (LopezFandino et al., 1993) at $40^{\circ} \mathrm{C}$. The total peak area of the chromatograms was integrated using Chromeleon 7.2 Data System Software (Thermo Scientific). The maximum peak area at plateau was considered as $100 \%$ of the CMP released.

\section{Light Scattering}

Zeta potential and the average apparent radius of the casein micelles were determined by Dynamic light scattering (Zetasizer Nano, Malvern Instruments, Worcestershire, UK). All samples were diluted 1,000 times with corresponding filtered $(0.2-\mu \mathrm{m}$ nylon filters, Fisher Scientific) UF permeates and analyzed.

Transmission DWS was also used to investigate the colloidal properties and to monitor the rennet gelation process of casein micelles in situ, as previously reported (Alexander et al., 2006). The output result from DWS is a time-dependent correlation function, as expressed by the following equation:

$g_{(t)} \approx \frac{\left(\frac{L}{l^{*}}+4 / 3\right)\left(\frac{6 t}{\tau}\right)^{1 / 2}}{\left(1+\frac{8 t}{3 \tau}\right) \operatorname{Sinh}\left[\frac{L}{l^{*}}\left(\frac{6 t}{\tau}\right)^{1 / 2}\right]+\frac{4}{3}\left\{\frac{6 t}{\tau} \cosh \left[\frac{L}{l^{*}}\left(\frac{6 t}{\tau}\right)^{1 / 2}\right]\right\}^{1 / 2}}$,

where $g$ is an autocorrelation function, $t$ is time, $L$ is the sample thickness and $\tau$ characteristic decay time, $\tau=1 / \mathbf{q}^{2} D, \mathbf{q}$ is the wave vector $(\mathbf{q}=2 \pi n / \lambda$, where $n$ is the refractive index of the continuous phase and $\lambda$ is the wavelength; Weitz et al., 1993), $D$ is the diffusion coefficient, and $l^{*}$ is the transport mean free path, which represents the length scale over which the direction of the light passing through a sample has been fully randomized (Alexander et al., 2006). The value of $l^{*}$ can be calculated from the total intensity of the scattered light from the sample, and the laser intensity was previously calibrated using standard latex spheres of diameter $260 \mathrm{~nm}$ (Portland Duke Scientific, Palo
Alto, CA). However, this relation only holds true in freely diffusive systems. Once the particle dynamics are changed to a subdiffusive motion, the quantity $t / \tau$ in [1] must be substituted by $k_{0}=\left[\Delta r^{2}(t)\right] / 6$, where $k$ is the mean square distance, $r$ is distance, and $t$ is the time over which one wants to average. In this case, the mean square displacement can be used to determine changes in the particles' degrees of freedom, which is defined as the mobility of a scattering particle around its average position (Sandra et al., 2007; Cucheval et al., 2009).

Before the measurement, all samples undiluted were transferred into an optical glass cuvette (Hellma Canada Ltd., Concord, Ontario, Canada) with a 5 -mm path length and then placed in a water bath maintained at $25^{\circ} \mathrm{C}$. A solid-state laser light with a wavelength of 532 $\mathrm{nm}$ and a power of $350 \mathrm{~mW}$ (Coherent, Santa Clara, CA) was used to illuminate the samples. Scattered light intensity was collected in transmission mode and analyzed using software designed specifically for the equipment (Mediavention Inc., ON, Canada). Correlation functions and intensity of transmitted scattered light were measured at intervals of $2 \mathrm{~min}$. The viscosity and refractive index of the continuous phase used to calculate the radius were $1.021 \times 10^{-3} \mathrm{~Pa} \cdot \mathrm{s}$ and 1.34 , respectively (Gaygadzhiev et al., 2008). For renneting measurements, correlation functions and intensity of transmitted scattered light were measured for $2 \mathrm{~min}$ (118-s collection, 2-s break) until gelation. The gelation process was performed at $30^{\circ} \mathrm{C}$. The aggregation point was defined graphically, as the time of rapid increase of the radius.

\section{Rheology}

The rheometer was used to measure the apparent viscosity of samples and follow the gel formation process. The apparent viscosity of different samples before renneting was measured using a shear rate ramp from 10 to $100 \mathrm{~s}^{-1}$ applied with a controlled stress rheometer (AR 1000, TA Instruments Ltd., New Castle, DE) at $25^{\circ} \mathrm{C}$. The sample was loaded on a cone and plate geometry with a set gap of $0.51 \mathrm{~mm}$. The values are reported for viscosity measured at $100 \mathrm{~s}^{-1}$.

The gel formation process of skim and concentrated milk was followed by oscillatory measurements, using a constant strain of 0.01 and a frequency of $1 \mathrm{~Hz}$. In this case, a concentric cylinder (28 and $30 \mathrm{~mm}$ inner and outer cylinders diameter, respectively) and an external water bath (Isotemp 3016, Fisher Scientific) were used to control the temperature at $30^{\circ} \mathrm{C}$. Aliquots $(20 \mathrm{~mL})$ of sample were transferred to the cylinder within $5 \mathrm{~min}$ after the addition of chymosin. The milk gelation point was defined as the point when the elastic modulus $\left(\mathrm{G}^{\prime}\right)$ and viscous modulus $\left(\mathrm{G}^{\prime \prime}\right)$ cross over $(\tan \delta=1$; Lucey 
et al., 1998). This point corresponds to a steep increase in the storage modulus $\left(\mathrm{G}^{\prime}\right)$ over time.

\section{Statistical Analysis}

Experiments were carried out at least in triplicate. Analysis of variance and Tukey honestly significant difference were carried out on the experimental measurements with $95 \%$ confidence level using Minitab statistical package release 15 (Minitab Inc., State College, PA).

\section{RESULTS AND DISCUSSION}

\section{Composition of Soluble Fraction and Zeta Potential of Casein Micelles}

Three different levels of concentration were tested, with and without addition of $300 \mathrm{mM} \mathrm{NaCl}$, corresponding to $1 \times, 3 \times$, and $5 \times$ of the original skim milk, and a total protein of $3.2,9$, and $13 \%$ (wt/vol) (Table 1 ). The amount of soluble protein was statistically different in samples of $1 \times$ milk containing $300 \mathrm{mM} \mathrm{NaCl}$ $(P<0.05)$ compared with control. On the other hand, no differences were detected for the $3 \times$ and $5 \times$ concentrated samples, compared with control. In all cases, about $30 \%$ of the total protein was recovered in the centrifugal supernatants.

As previously reported in the literature (Grufferty and Fox, 1985; Gaucheron et al., 2000; Huppertz and Fox, 2006), the addition of $\mathrm{NaCl}$ in milk significantly $(P<0.05 \%)$ reduced the $\mathrm{pH}$ of both unconcentrated and concentrated milk, from 6.66 to 6.54 for milk containing $300 \mathrm{mM}$ (Table 1). It is also important to note that the $\mathrm{pH}$ values of milk were not significantly different from $1 \times$ milk after concentration, in contrast with what was reported in the literature (Waungana et al., 1999; Karlsson et al., 2007). The difference is due to the fact that, in previous work, ultrafiltration was combined with diafiltration, causing further changes in mineral equilibrium.
Table 1 also summarizes the values of zeta potential of casein micelles, measured after redilution in their corresponding serum. In control milk the zeta potential was around $-21 \mathrm{mV}$, and concentration had no significant effect (Table 1). The addition of $300 \mathrm{mM} \mathrm{NaCl}$ significantly $(P<0.05)$ decreased the zeta potential of casein micelles, compared with control without $\mathrm{NaCl}$, and in the concentrated samples, it was significantly $(P$ $<0.05)$ lower after redilution. The decrease with $\mathrm{NaCl}$ was induced by the screening effect of $\mathrm{NaCl}$, reduced the electrophoretic mobility of the casein micelles, by a decrease in the electrostatic charge and thickness of the electrical double layer (Bouchoux et al., 2009; Bouchoux et al., 2010). However, it further decreased with concentration history, possibly because of a difference in the overall soluble ions present in the serum phase because of membrane filtration.

All samples (with or without $\mathrm{NaCl}$ ) showed no significant differences in hydrodynamic radius after redilution (86 $\pm 2 \mathrm{~nm})$, indicating no aggregation of the casein micelles, in agreement with previous reports (Huppertz and Fox, 2006). Figure 1 describes the changes in total and diffusible calcium and phosphate at the 3 concentrations for milk with and without $\mathrm{NaCl}$. The total calcium and phosphate increased with concentration, and the addition of $\mathrm{NaCl}$ caused a decrease in the amount of calcium and phosphate recovered in the suspensions for $3 \times$ and $5 \times$ milk. After the addition of $\mathrm{NaCl}$, the diffusible calcium and phosphate increased significantly compared with milk without $\mathrm{NaCl}$ (Figure 1C, 1D). These results clearly indicated that the addition of $\mathrm{NaCl}$ caused the solubilization of calcium and phosphate from the casein micelles. These changes would further explain the decrease in electrophoretic mobility of the casein micelles in concentrated suspensions with $\mathrm{NaCl}$ (Table 1). The results are in full agreement with previous reports (Le Graët and Gaucheron, 1999; Huppertz and Fox, 2006; Sbodio et al., 2006). Addition of $\mathrm{NaCl}$ decreased the colloidal calcium present in the micellar suspensions (calculated as the difference between total and diffusible); the value of colloidal calcium decreased

Table 1. Effect of $\mathrm{NaCl}$ and concentration on $\mathrm{pH}$, total and soluble proteins of milk, and zeta potential of casein micelles ${ }^{1}$

\begin{tabular}{|c|c|c|c|c|c|}
\hline $\begin{array}{l}\mathrm{NaCl} \\
\text { concentration }\end{array}$ & $\begin{array}{l}\text { Concentration } \\
\text { factor }\end{array}$ & $\mathrm{pH}$ & $\begin{array}{c}\text { Total } \\
\text { protein }(\%)\end{array}$ & $\begin{array}{c}\text { Soluble } \\
\text { protein (\%) }\end{array}$ & $\begin{array}{c}\text { Zeta } \\
\text { potential }(\mathrm{mV})\end{array}$ \\
\hline \multirow[t]{2}{*}{$0 \mathrm{~m} M$} & $1 \times$ & $6.66 \pm 0.01^{\mathrm{a}}$ & $3.29 \pm 0.01^{\mathrm{a}}$ & $0.84 \pm 0.04^{\mathrm{a}}$ & $-21.7 \pm 1.2^{\mathrm{a}}$ \\
\hline & $3 \times$ & $6.64 \pm 0.01^{\mathrm{a}}$ & $9.31 \pm 0.45^{\mathrm{b}}$ & $2.47 \pm 0.14^{\mathrm{c}}$ & $-20.3 \pm 0.6^{\mathrm{a}}$ \\
\hline \multirow[t]{3}{*}{$300 \mathrm{~m} M$} & $1 \times$ & $6.53 \pm 0.01^{\mathrm{b}}$ & $3.28 \pm 0.04^{\mathrm{a}}$ & $1.02 \pm 0.04^{\mathrm{b}}$ & $-19.1 \pm 0.9^{\mathrm{a}}$ \\
\hline & $3 \times$ & $6.54 \pm 0.01^{\mathrm{b}}$ & $8.79 \pm 0.36^{\mathrm{b}}$ & $2.47 \pm 0.08^{\mathrm{c}}$ & $-15.9 \pm 0.5^{\mathrm{b}}$ \\
\hline & $5 \times$ & $6.54 \pm 0.01^{\mathrm{b}}$ & $13.5 \pm 0.58^{\mathrm{c}}$ & $4.41 \pm 0.15^{\mathrm{d}}$ & $-15.6 \pm 0.5^{\mathrm{b}}$ \\
\hline
\end{tabular}

\footnotetext{
${ }^{\mathrm{a}-\mathrm{d}}$ Means within a column with different superscript letters are significantly different $(P<0.05)$.

${ }^{1}$ Values are means of data from triplicate experiments. Error indicates standard deviation.
} 


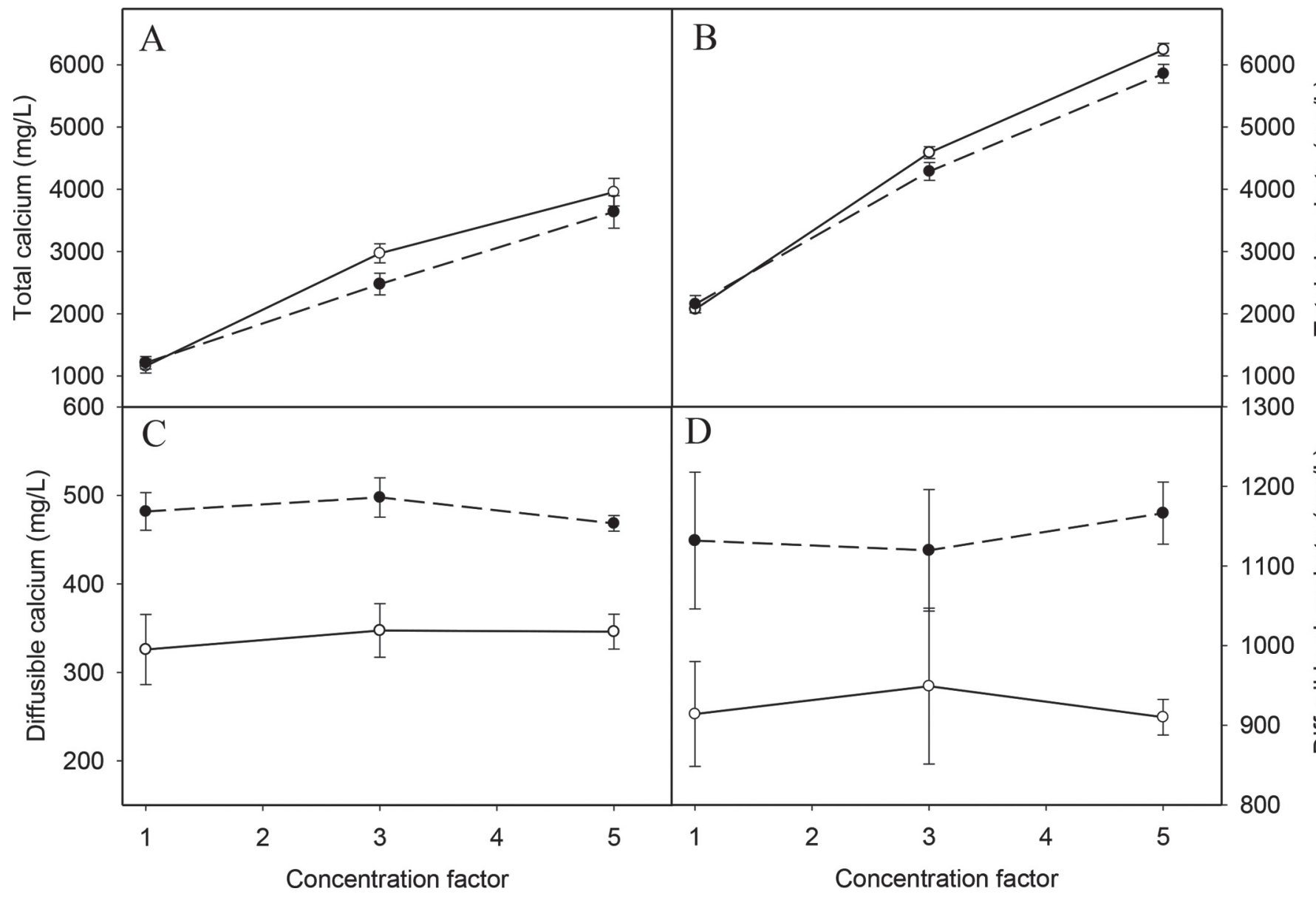

Figure 1. Influence of $\mathrm{NaCl}$ addition on total (A, B) and diffusible (C, D) calcium (A, C) and phosphate (B, D). Samples were concentrated to $1 \times, 3 \times$, and $5 \times$ with (filled circles) and without (empty circles) $300 \mathrm{mM} \mathrm{NaCl}$. Values are average values from triplicate experiments, with the standard deviation indicated by error bars. Lines are drawn to guide the eye.

from $309 \pm 26 \mathrm{mg} / \mathrm{kg}$ per gram of casein for $1 \times$ milk to $270 \pm 30 \mathrm{mg} / \mathrm{kg}$ per gram of casein after the addition of $300 \mathrm{~m} \mathrm{M} \mathrm{NaCl}$. The lower level of colloidal calcium was consistent in the $\mathrm{NaCl}$ suspensions, independently on concentration.

\section{Apparent Viscosity}

Figure 2 shows the changes in the apparent viscosity, measured at a shear rate of $100 \mathrm{~s}^{-1}$, for milk samples concentrated with or without $\mathrm{NaCl}$. The viscosity of milk increased with concentration. With the addition of $\mathrm{NaCl}$, the viscosity of the concentrates significantly $(P$ $<0.05)$ increased, whereas the $1 \times$ milk did not change. In $5 \times$ concentrated milk the values changed from $8.7 \pm$ 0.1 to $12.1 \pm 0.3 \mathrm{mPa} \cdot \mathrm{s}$.

It has been previously reported that the addition of $\mathrm{NaCl}$ causes a reduction of the mean free distance between casein micelles (Karlsson et al., 2007), and the closer proximity of the micelles is the reason for the in-

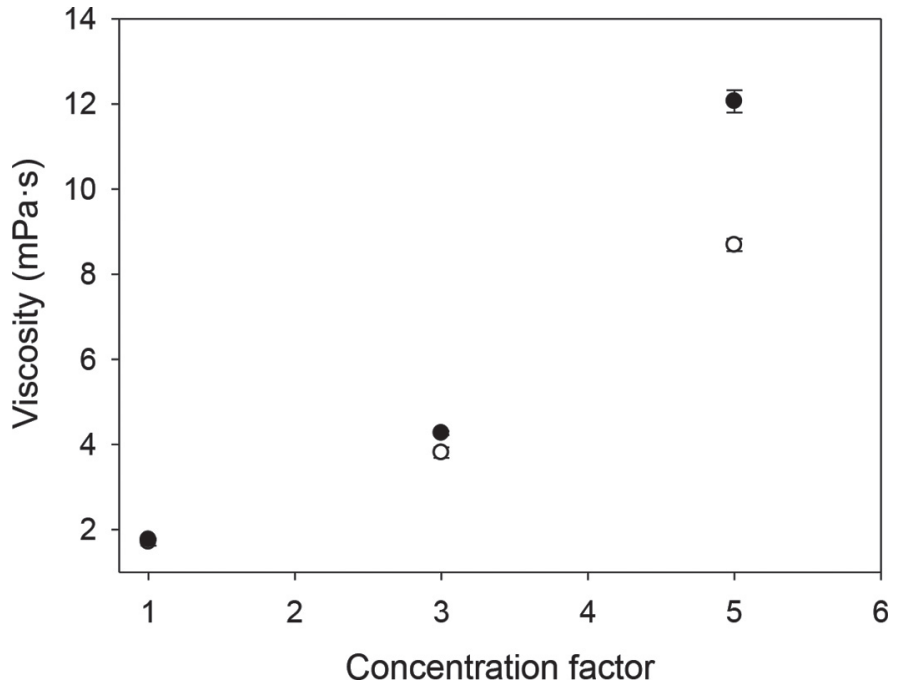

Figure 2. Viscosities of milk at different concentrations, with (filled circles) or without (empty circles) $300 \mathrm{~m} \mathrm{M} \mathrm{NaCl}$. Values are average values from triplicate experiments, with the standard deviation indicated by vertical error bars. 
crease in the milk viscosity. It has been recently shown that the addition of $\mathrm{NaCl}$ also increases the concentration of soluble casein, contributing to an increase in the bulk viscosity of the casein suspensions (Famelart et al., 1999; Zhao and Corredig, 2014). Other authors reported a similar effect of $\mathrm{NaCl}$ in sodium caseinate solutions, and the increase in viscosity was attributed to an increase in osmotic pressure as well as an increase in the protein voluminosity (Abd El-Salam et al., 1987). The presence of $\mathrm{NaCl}$ decreases the overall charge of the proteins by shielding those charges, causing an increase in protein-protein interactions.

\section{Turbidity}

The turbidity parameter $\left(1 / l^{*}\right)$ was measured by transmission DWS, without dilution (Figure 3). As expected turbidity increased in $1 \times$ to $3 \times$ concentrated milk, because of the increased scattering events in a given space (Sandra et al., 2011). The closer spacing between casein micelles will cause the light scattering to be randomized faster, resulting in the decrease of the $l^{*}$.

The additional increase in concentration from $3 \times$ to $5 \times$ did not further increase the turbidity, and no significant difference could be detected between these 2 concentrations. According to previous research, the turbidity of milk fit well to the theoretically predicted values for a hard-sphere system up to a concentration factor 3.2 (Dahbi et al., 2010). A maximum turbidity value was obtained at a concentration factor 3.9, and

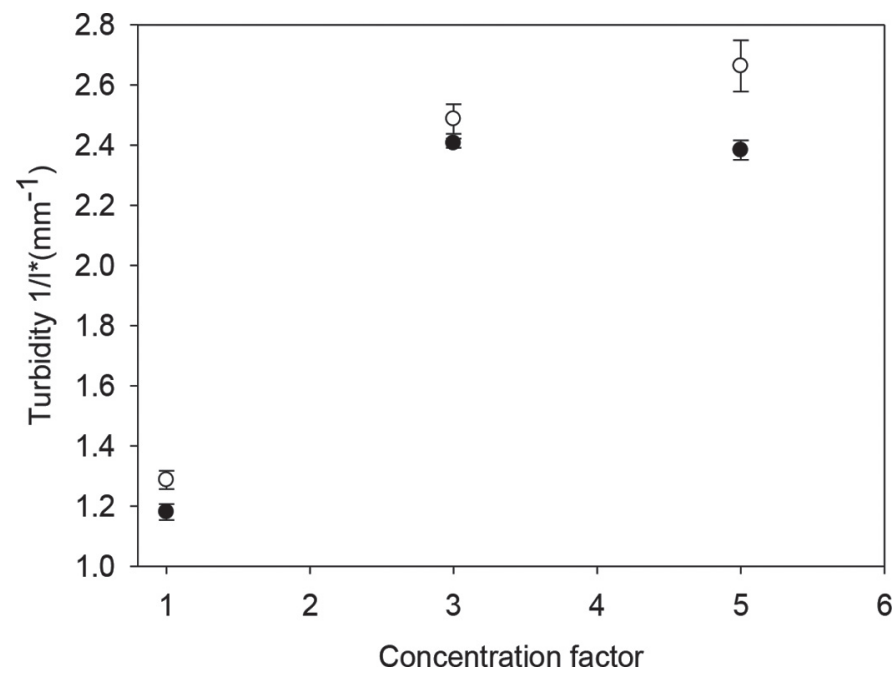

Figure 3. Turbidity parameters of milk at different concentrations, with (filled circles) or without (empty circles) $300 \mathrm{mM} \mathrm{NaCl}$. Values are average values from triplicate experiments, with the standard deviation indicated by vertical error bars. Variable $l^{*}$ is the transport mean free path, which represents the length scale over which the direction of the light passing through a sample has been fully randomized. further increase of concentration factor led to decrease of turbidity, because of the occurrence of interparticle interactions at high concentration (Krishnakutti Nair et al., 2014). The addition of $300 \mathrm{mM} \mathrm{NaCl}$ to milk caused a significant $(P<0.05)$ decrease of the turbidity parameter at all concentrations. The turbidity parameter is a function of the optical properties of the scattering particles as well as a structure factor. At the low concentration $(<4 \times$ for milk), the system can be regarded as free diffusing (Krishnakutti Nair et al., 2014). The negative charge on the surface of casein micelles decreased only slightly with $\mathrm{NaCl}$ addition, suggesting that sufficient charge repulsion still existed between these protein particles. The interparticle interactions, therefore, could be considered negligible, $S(q)=1$. Therefore, the turbidity parameter is only influenced by the scattering form factor $F(q)$, where $q$ is the scattering vector, which is related to the size of casein micelles and refractive index contrast between the scatterers and serum. From the results of dynamic light scattering, all samples, after redilution, showed no significant change in the radius of casein micelles with addition of $\mathrm{NaCl}$. The decrease in the turbidity parameter with $\mathrm{NaCl}$ in concentrated suspensions can be attributed to the differences in the refractive index between the protein particles and the serum, and it is due to the changes of serum refractive index as a result of dissolution of colloidal calcium phosphate and casein release (Zhao and Corredig, 2014).

\section{Rennet-Induced Gelation}

The effect of $\mathrm{NaCl}$ on the kinetics of CMP release is shown in Figure 4. As previously shown for milk concentrated by ultrafiltration (Sandra et al., 2011), CMP release did not differ with concentration in control milk (no $\mathrm{NaCl}$; data not shown). The presence of $300 \mathrm{mM}$ $\mathrm{NaCl}$ caused a decrease in the rate of the CMP release, in agreement with previous literature (Gatti and Pires, 1994; Famelart et al., 1999). However, the kinetics for suspensions containing $\mathrm{NaCl}$ were not significantly different $(P<0.05)$, regardless of concentration factor. All 3 samples reached about 85\% CMP cleavage at about 80 min, compared with those of control milk, which required only $60 \mathrm{~min}$ to reach the same critical point for aggregation.

Figure 5 shows the changes of the DWS parameters (radius and $1 / l^{*}$ ) as a function of time, after addition of rennet. The apparent radii were corrected by the Beenakker-Mazur formalism (Beenakker and Mazur, 1984). The $1 / l^{*}$ increased with increasing concentration (Figure 3), and for better comparison of the gelation behavior, it was normalized (Figure 5). The $1 / l^{*}$ parameter was initially constant, showing an increase 
with time before the gelation point, indicated by a steep increase in the radius. The behavior of $1 / l^{*}$ was fully consistent with previous literature observations (Sandra et al., 2011). It has been previously shown that the turbidity parameter shows a sharp increase in untreated milk at about $70 \%$ CMP release. At this stage, the casein micelles are still free diffusing, but their spatial organization is changing because of a decrease in steric repulsion between the particles and a change in the refractive index contrast. Figure 5 shows that samples with and without $\mathrm{NaCl}$ had a similar behavior, with a leveling off of the $1 / l^{*}$ for $1 \times$ milk at the point of gelation, as shown in the literature (Sandra et al., 2011). At the higher concentrations, the turbidity parameter did not level off, both for $\mathrm{NaCl}$ and control samples. This may suggest that rearrangements occur to the structure of the gel. Whereas at $5 \times$ concentration behavior of the $1 / l^{*}$ with the addition of $\mathrm{NaCl}$ did not differ, a delay in the onset was shown for casein suspensions containing $\mathrm{NaCl}$ at $1 \times$ and $3 \times$ concentrations. This was partly caused by the delay in the CMP release (Figure 4). The gelation point, as measured both by DWS or rheology (Figure 5 and Table 2), was indeed retarded in casein suspensions containing $\mathrm{NaCl}$ compared with the corresponding control, at all concentrations. In control samples, aggregation occurred around $60 \mathrm{~min}$, consistent with the data reported for CMP release (Table 2). The aggregation point did not change with concentration. The addition of $\mathrm{NaCl}$ caused a delayed increase of radius (Figure 5). Unlike the case of control milk with no $\mathrm{NaCl}$, the onset of aggregation differed for these

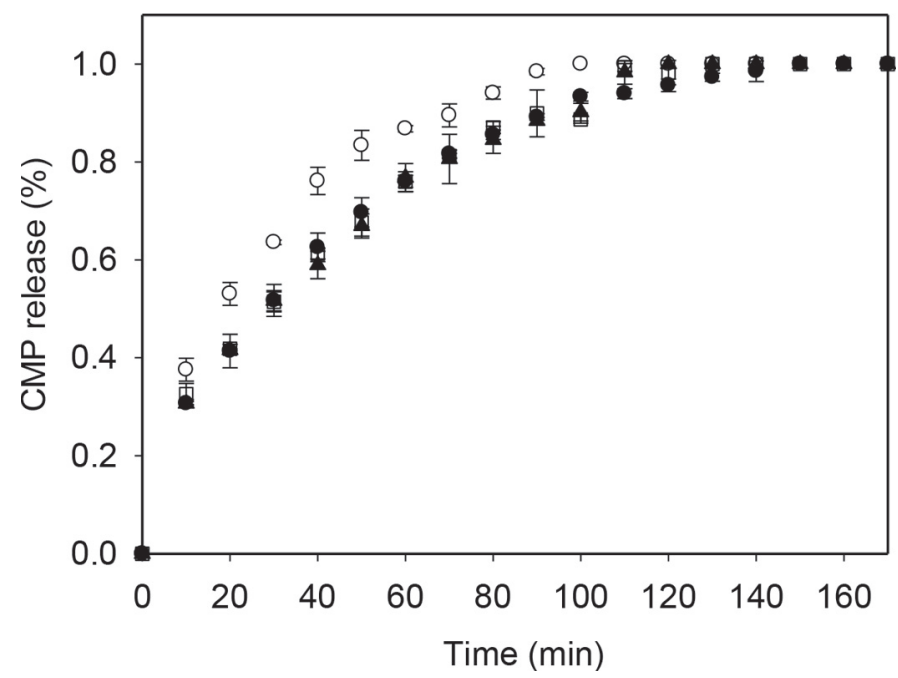

Figure 4. Amount of caseinomacropeptide (CMP) released as a function of time from the addition of the rennet into the milk samples. $1 \times$ untreated milk $(\bigcirc)$ and $1 \times(\bullet), 3 \times(\boldsymbol{\Delta})$, and $5 \times(\boldsymbol{\square})$ milk containing $300 \mathrm{mM} \mathrm{NaCl}$. Data are the average of 3 separate experiments, with error bars representing standard deviation. samples, whereby the rapid increase of radius happened after $100 \mathrm{~min}$ for $1 \times$ milk, and the time shifted to 80 and $65 \mathrm{~min}$ for $3 \times$ and $5 \times$ milk, respectively. The differences in the aggregation behavior as a function of time with concentration could not be attributed to the primary stage of renneting, as the CMP release was not significantly different between samples containing $\mathrm{NaCl}$ at different concentration. These results would suggest that when concentrated, casein micelles destabilization will occur at a lower CMP release in the presence of

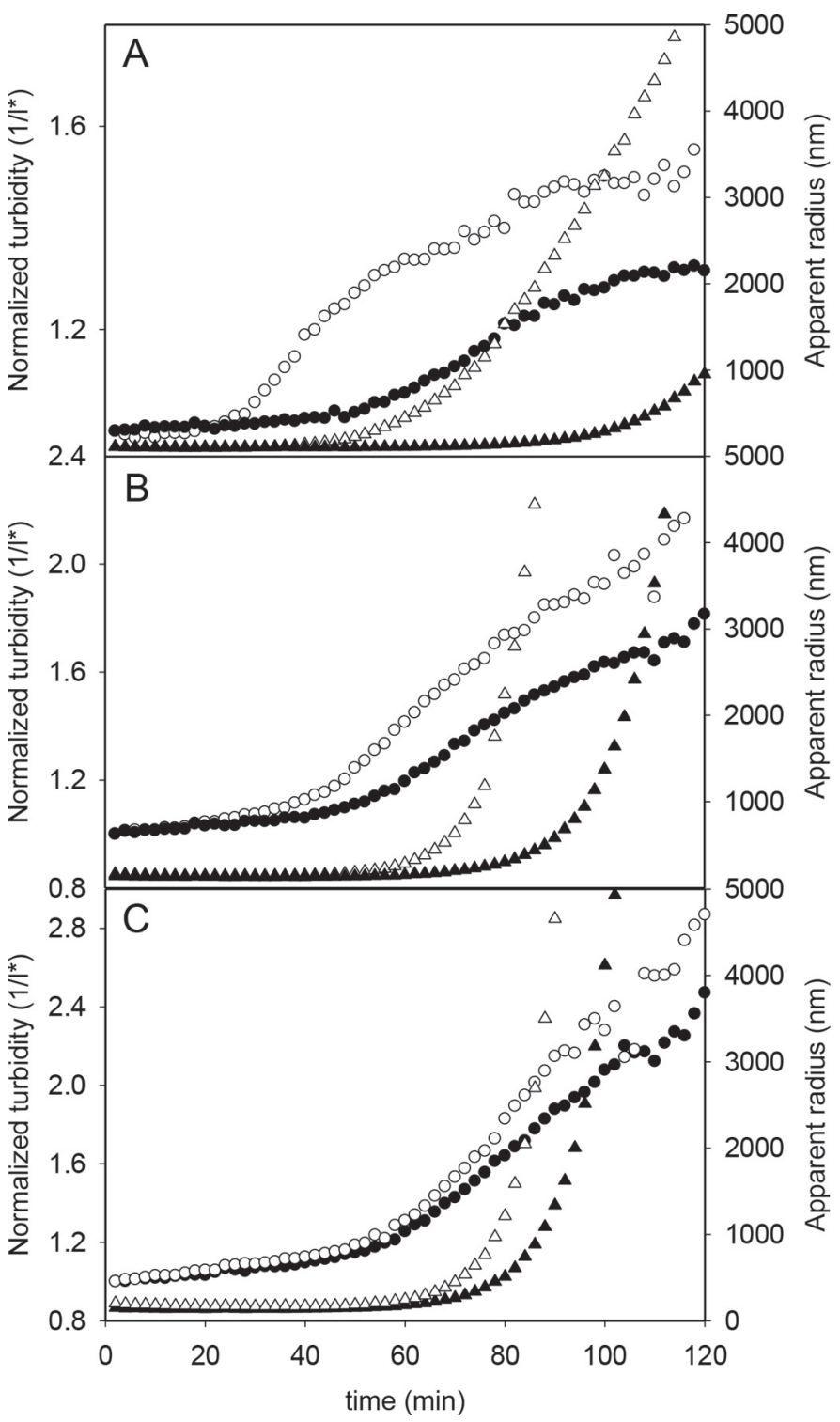

Figure 5. Development of normalized $1 / l^{*}(\mathbf{\bullet}, \bigcirc)$ and apparent radius $(\boldsymbol{\Lambda}, \Delta)$ during rennet gelation of casein micelles suspensions with (filled symbols) and without (empty symbols) NaCl. Data are representative of 3 separate experiments for $1 \times(\mathrm{A}), 3 \times(\mathrm{B})$, and $5 \times(\mathrm{C})$ milk. Variable $l^{*}$ is the transport mean free path, which represents the length scale over which the direction of the light passing through a sample has been fully randomized. 


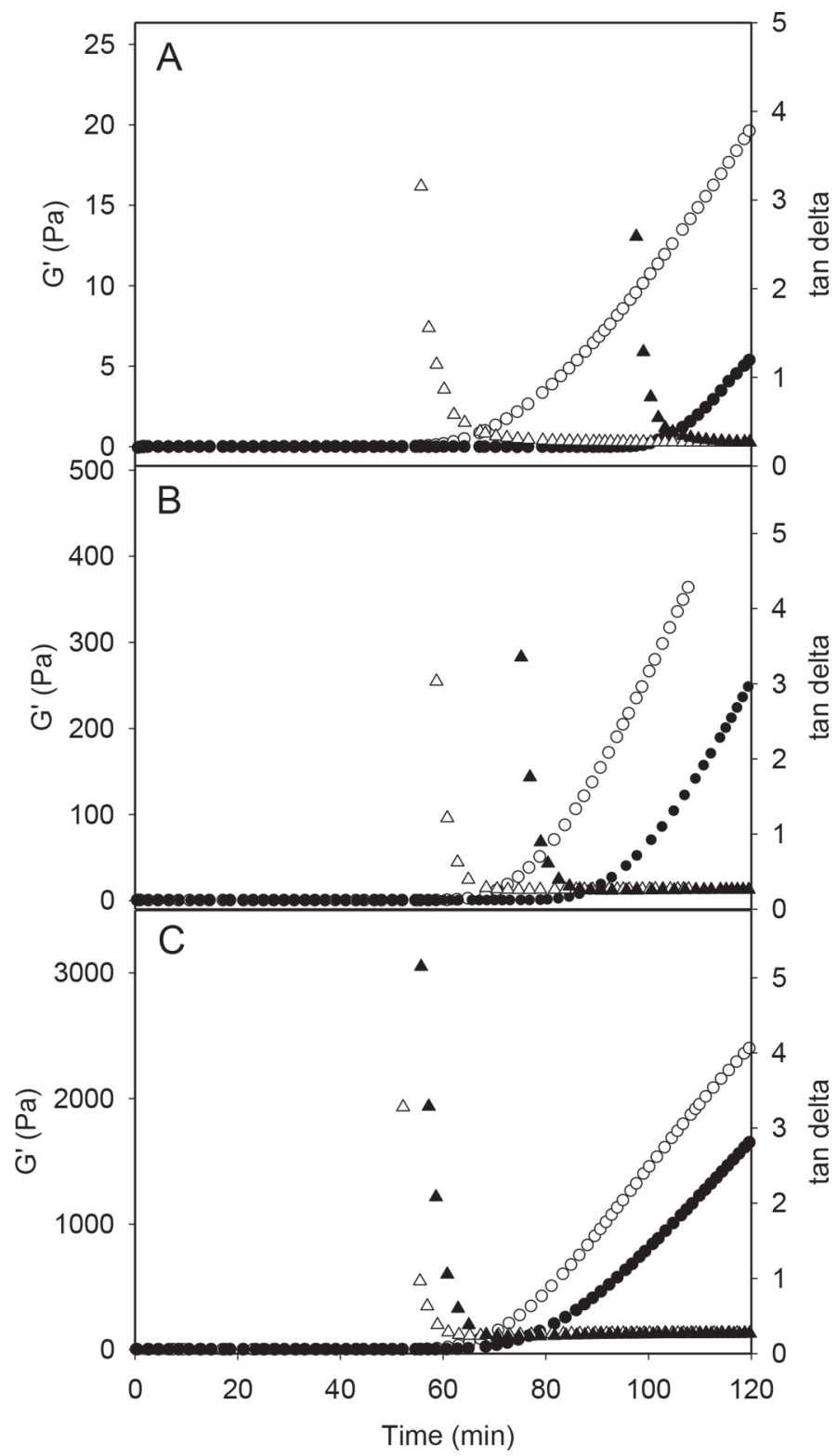

Figure 6. Development of elastic modulus $\mathrm{G}^{\prime}(\mathbf{\bullet}, \bigcirc)$ and $\tan \delta$ $(\boldsymbol{\Lambda}, \Delta)$ during rennet gelation of casein micelles suspensions with (filled symbols) and without (empty symbols) $\mathrm{NaCl}$. Data are representative runs for $1 \times(\mathrm{A}), 3 \times(\mathrm{B})$, and $5 \times(\mathrm{C})$ milk. charge shielding $(300 \mathrm{~m} M \mathrm{NaCl})$. These results were in full agreement with previous reports (Sharma et al., 1994; Le Feunteun et al., 2012).

The development of elastic $\left(\mathrm{G}^{\prime}\right)$ modulus and the loss tangent $(\tan \delta$ ) during the rennet gelation process is summarized in Figure 6. Both samples with or without $\mathrm{NaCl}$ showed the formation of a stiff network but with different gelation times. Table 2 also summarizes the stiffness of the gels after $45 \mathrm{~min}$ from the gelation point. The curd-firming rate increased with concentration, in full agreement with previous results (Sharma and Hill, 1993; Guinee et al., 1996). It is well understood that gels formed from UF-concentrated milk are stiffer compared with gels made from control unconcentrated milk, simply because of the higher numbers of bonds forming between the proteins. In addition, the increased volume fraction of casein micelles due to UF concentration reduces the average distance between micelles, which increased the frequency of collisions and the contact area in the gel network, contributing to the increased curd-firming rate (Waungana et al., 1997; Mishra et al., 2005). The differences in firming rate are in line with previous results. It has been reported that addition of $\mathrm{NaCl}$ not only can affect the cleavage rate of $\kappa-\mathrm{CN}$ but can also influence the aggregation of renneted casein micelles; at $\mathrm{NaCl}$ concentrations higher than $200 \mathrm{mM}$, the rate of aggregation significantly decreases (Bansal et al., 2008).

In the presence of $\mathrm{NaCl}$, consistent with the DWS observations, the time of gelation increased, and a significant $(P<0.05)$ difference with concentration existed. All samples showed lower stiffness than the same samples without $\mathrm{NaCl}$. The loss tangent values for samples without $\mathrm{NaCl}$ addition reached a plateau around 0.27 regardless of concentration, as previously reported (Sandra et al., 2011). Similar loss tangent plateau values $(0.26)$ were reached for samples containing $300 \mathrm{~m} M \mathrm{NaCl}$. Higher $\tan \delta$ value indicates higher rearrangement and flexibility of the structure and more susceptibility to syneresis (Mishra et al., 2005). All the gels formed in this research had similar $\tan \delta$ values,

Table 2. Rennet gelation parameters of concentrated milk with or without the addition of $\mathrm{NaCl}^{1}$

\begin{tabular}{|c|c|c|c|c|c|}
\hline $\begin{array}{l}\mathrm{NaCl} \\
\text { concentration }\end{array}$ & $\begin{array}{l}\text { Concentration } \\
\text { factor }\end{array}$ & $\begin{array}{l}\text { Gelation } \\
\text { time (min) }\end{array}$ & $\begin{array}{l}\text { Aggregation } \\
\text { time (min) }\end{array}$ & $\mathrm{G}^{\prime}(\mathrm{Pa})$ & $\begin{array}{c}\operatorname{Tan} \delta \\
\text { at plateau }\end{array}$ \\
\hline \multirow[t]{2}{*}{$0 \mathrm{mM}$} & $1 \times$ & $59.4 \pm 1.4^{\mathrm{a}}$ & $58.8 \pm 2.0^{\mathrm{a}}$ & $14 \pm 1^{\mathrm{a}}$ & $0.2662 \pm 0.0009^{\mathrm{a}}$ \\
\hline & $3 \times$ & $60.0 \pm 1.1^{\mathrm{a}}$ & $60.6 \pm 1.7^{\mathrm{a}}$ & $353 \pm 12^{\mathrm{b}}$ & $0.2666 \pm 0.0008^{\mathrm{a}}$ \\
\hline \multirow[t]{3}{*}{$300 \mathrm{~m} M$} & $1 \times$ & $104.0 \pm 4.4^{\mathrm{b}}$ & $102.6 \pm 0.7^{\mathrm{b}}$ & $13 \pm 0.7^{\mathrm{a}}$ & $0.2596 \pm 0.0010^{\mathrm{c}}$ \\
\hline & $3 \times$ & $80.6 \pm 2.8^{c}$ & $83.1 \pm 0.9^{\mathrm{c}}$ & $286 \pm 22^{\mathrm{d}}$ & $0.2606 \pm 0.0040^{\mathrm{a}}$ \\
\hline & $5 \times$ & $67.1 \pm 4.8^{\mathrm{d}}$ & $70.0 \pm 2.1^{\mathrm{d}}$ & $933 \pm 123^{\mathrm{e}}$ & $0.2615 \pm 0.0033^{\mathrm{c}}$ \\
\hline
\end{tabular}

\footnotetext{
${ }^{\mathrm{a}-\mathrm{e}}$ Values within different superscript letters are significantly different $(P<0.05)$.

${ }^{1}$ Values are means of 3 separate experiments, with error indicating standard deviation. The G' was measured after 45 min from the gelation point, defined as $\delta<45^{\circ}$. Aggregation time was measured by diffusing wave spectroscopy as onset of radius increase.
} 
indicating both the $\mathrm{NaCl}$ addition and concentration have no effect on the final milk gel types. It is important to note that at the high concentrations, in both control and $\mathrm{NaCl}$ suspensions, the turbidity parameter did not reach a plateau. The negative effect of $\mathrm{NaCl}$ on the coagulation of milk has been ascribed to the screening of the positively charged cluster of $\kappa-\mathrm{CN}$ and of the chymosin, which inhibit the interaction between chymosin and $\kappa-\mathrm{CN}$ and decrease the enzymatic rate (Visser et al., 1987). However, the addition of $\mathrm{NaCl}$ influenced both the primary and secondary stage of rennet coagulation. This effect could only partly be attributed to a decrease in the rate of $\kappa$ - $\mathrm{CN}$ hydrolysis. In the presence of $\mathrm{NaCl}$, gelation time differed depending on concentration, and at the higher concentrations, gelation occurred before $80 \%$ of the CMP was released. This was not the case for control milk. The change is not related only to the decreased average distance between casein micelles, but to the decreased charge and increased solvation after $\mathrm{NaCl}$ addition (Famelart et al., 1999) and, most importantly, to the release of colloidal calcium and dissociation of the casein micelles. Hence, it can be concluded that although the rheological properties of the gels were similar, protein rearrangements still occurred in these gels.

\section{CONCLUSIONS}

Addition of $\mathrm{NaCl}$ led to a significant increase in the rennet coagulation time. It is important to note that during the UF process, the sodium chloride present in the serum phase was also partly removed. The final concentration of $\mathrm{NaCl}$ was 280 and $260 \mathrm{mmol} / \mathrm{L}$ for $3 \times$ and $5 \times$ milk, respectively. The presence of high concentration $\mathrm{NaCl}$ inhibited gelation and showed a decrease in the gel stiffness compared with the corresponding control. The results of this work put into question the current understanding of the effect of concentration on rennet-induced aggregation of casein micelles and the role that soluble and colloidal calcium phosphate play in the secondary stage of aggregation. A better understanding of the aggregation in concentrated milk can be beneficial to the application of modified casein micelles as an ingredient in food products.

\section{ACKNOWLEDGMENTS}

Financial support was provided by the Natural Science and Engineering Council of Canada and by the Ontario Dairy Council through the industrial research chair program.

\section{REFERENCES}

Abd El-Salam, M. H., S. El-Shibiny, M. B. Mahfouz, and H. F. ElDein. 1987. Effect of $\mathrm{pH}$ and sodium chloride on the viscosity of skim milk retentates. Lait 67:111-119.

Alexander, M., M. Corredig, and D. G. Dalgleish. 2006. Diffusing wave spectroscopy of gelling food systems: The importance of the photon transport mean free path $\left(1^{*}\right)$ parameter. Food Hydrocoll. $20: 325-331$.

Bansal, N., P. F. Fox, and P. L. H. McSweeney. 2008. Factors that affect the aggregation of rennet-altered casein micelles at low temperatures. Int. J. Dairy Technol. 61:56-61.

Beenakker, C. W. J., and P. Mazur. 1984. Diffusion of spheres in a concentrated suspension. Phys. A Stat. Mech. Appl. 126A:349-370.

Bouchoux, A., B. Debbou, G. Gésan-Guiziou, M. Famelart, J. Doublier, and B. Cabane. 2009. Rheology and phase behavior of dense casein micelle dispersions. J. Chem. Phys. 131:165106.

Bouchoux, A., G. Gésan-Guiziou, J. Pérez, and B. Cabane. 2010. How to squeeze a sponge: Casein micelles under osmotic stress, a SAXS study. Biophys. J. 99:3754-3762.

Carr, A. J., P. A. Munro, and O. H. Campanella. 2002. Effect of added monovalent or divalent cations on the rheology of sodium caseinate solutions. Int. Dairy J. 12:487-492.

Cucheval, A., R. R. Vincent, Y. Hemar, D. Otter, and M. A. K. Williams. 2009. Diffusing wave spectroscopy investigations of acid milk gels containing pectin. Colloid Polym. Sci. 287:695-704.

Dahbi, L., M. Alexander, V. Trappe, J. K. G. Dhont, and P. Schurtenberger. 2010. Rheology and structural arrest of casein suspensions. J. Colloid Interface Sci. 342:564-570.

Dalgleish, D. G. 1980. Effect of milk concentration on the rennet coagulation time. J. Dairy Res. 47:231-235.

Dalgleish, D. G. 2011. On the structural models of bovine casein micelles-Review and possible improvements. Soft Matter 7:22652272

Dalgleish, D. G., and M. Corredig. 2012. The structure of the casein micelle of milk and its changes during processing. Annu. Rev. Food Sci. Technol. 3:449-467.

De Kruif, C. G., and E. B. Zhulina. 1996. א-Casein as a polyelectrolyte brush on the surface of casein micelles. Colloids Surf. A: Physicochem. Eng. Asp. 117:151-159.

Famelart, M. H., Y. Le Graët, and K. Raulot. 1999. Casein micelle dispersions into water, $\mathrm{NaCl}$ and $\mathrm{CaCl}_{2}$ : Physicochemical characteristics of micelles and rennet coagulation. Int. Dairy J. 9:293-297.

Gatti, C., and M. Pires. 1994. Effect of monovalent cations on the kinetics of renneted milk coagulation. J. Dairy Res. 62:667-672.

Gaucheron, F., Y. Le Graët, and V. Briard. 2000. Effect of NaCl addition on the mineral equilibrium of concentrated and acidified casein micelles. Milchwissenschaft 55:82-86.

Gaygadzhiev, Z., M. Corredig, and M. Alexander. 2008. Diffusing wave spectroscopy study of the colloidal interactions occurring between casein micelles and emulsion droplets: Comparison to hard-sphere behavior. Langmuir 24:3794-3800.

Grufferty, M. B., and P. F. Fox. 1985. Effect of added $\mathrm{NaCl}$ on some physicochemical properties of milk. Irish J. Food Sci. Technol. 9:1-9.

Guinee, T., D. O'Callaghan, and P. N. O. Pudja. 1996. Rennet coagulation properties of retentates obtained by UF. Int. Dairy J. 6:581-596.

Holt, C. 1992. Structure and stability of bovine casein micelles. Adv. Protein Chem. 43:63-151.

Holt, C. 1998. Casein micelle substructure and calcium phosphate interactions studied by Sephacryl column chromatography. J. Dairy Sci. 81:2994-3003.

Holt, C. 2004. An equilibrium thermodynamic model of the sequestration of calcium phosphate by casein micelles and its application to the calculation of the partition of salts in milk. Eur. Biophys. J. 33:421-434.

Horne, D. S. 2006. Casein micelle structure: Models and muddles. Curr. Opin. Colloid Interface Sci. 11:148-153. 
Huppertz, T., and P. F. Fox. 2006. Effect of $\mathrm{NaCl}$ on some physicochemical properties of concentrated bovine milk. Int. Dairy J. 16:1142-1148.

Karlsson, A. O., R. Ipsen, and Y. Ardö. 2007. Rheological properties and microstructure during rennet induced coagulation of UF concentrated skim milk. Int. Dairy J. 17:674-682.

Krishnakutti Nair, P. K., M. Alexander, D. G. Dalgleish, and M. Corredig. 2014. Physico-chemical properties of casein micelles in unheated skim milk concentrated by osmotic stressing: Interactions and changes in the composition of the serum phase. Food Hydrocoll. 34:46-53.

Le Feunteun, S., M. Ouethrani, and F. Mariette. 2012. The rennet coagulation mechanisms of a concentrated casein suspensions as observed by PFG-NMR diffusion measurements. Food Hydrocoll. 27:456-463.

Le Graët, Y., and F. Gaucheron. 1999. pH-induced solubilization of minerals from casein micelles: Influence of casein concentration and ionic strength. J. Dairy Res. 66:215-224.

Liu, X. T., H. Zhang, F. Wang, J. Luo, H. Y. Guo, and F. Z. Ren. 2014. Rheological and structural properties of differently acidified and renneted milk gels. J. Dairy Sci. 97:3292-3299.

Lopez-Fandino, R., M. Isabel Acedo, and R. Mercedes. 1993. Comparative study by HPLC of caseinomacropeptides from cows', ewes' and goats' milk. J. Dairy Res. 60:117-121.

Lucey, J. A. 2002. Formation and physical properties of milk protein gels. J. Dairy Sci. 85:281-294.

Lucey, J. A., M. Tamehana, H. Singh, and M. Peter. 1998. Effect of interactions between denatured whey proteins and casein micelles on the formation and rheological properties of acid skim milk gels. J. Dairy Res. 65:555-567.

Mao, X. Y., P. S. Tong, S. Gualco, and S. Vink. 2012. Effect of $\mathrm{NaCl}$ addition during diafiltration on the solubility, hydrophobicity, and disulfide bonds of $80 \%$ milk protein concentrate powder. J. Dairy Sci. 95:3481-3488.

Mishra, R., S. Govindasamy-Lucey, and J. Lucey. 2005. Rheological properties of rennet-induced gels during the coagulation and cutting process: Impact of processing conditions. J. Texture Stud. 36:190-212.

Rahimi-Yazdi, S., M. A. Ferrer, and M. Corredig. 2010. Nonsuppressed ion chromatographic determination of total calcium in milk. J. Dairy Sci. 93:1788-1793.
Sandra, S., M. Alexander, and D. G. Dalgleish. 2007. The rennet coagulation mechanism of skim milk as observed by transmission diffusing wave spectroscopy. J. Colloid Interface Sci. 308:364-373.

Sandra, S., C. Cooper, M. Alexander, and M. Corredig. 2011. Coagulation properties of ultrafiltered milk retentates measured using rheology and diffusing wave spectroscopy. Food Res. Int. 44:951-956.

Sbodio, O. A., E. J. Tercero, R. Coutaz, and G. R. Revelli. 2006. Effect of rennet and sodium chloride concentration on milk coagulation properties. Cienc. Tecnol. Aliment. 5:182-188.

Sharma, S. K., and A. R. Hill. 1993. Effect of milk concentration, $\mathrm{pH}$ and temperature on aggregation kinetics and coagulation properties of ultrafiltered (UF) milk. Food Res. Int. 26:81-87.

Sharma, S. K., G. S. Mittal, and A. R. Hill. 1994. Effect of milk concentration, $\mathrm{pH}$ and temperature on kappa-casein hydrolysis at aggregation, coagulation and curd cutting times of ultrafiltered milk. Milchwissenschaft 49:450-453.

Van Hooydonk, A. C. M., H. G. Hagedoorn, and I. J. Boerrigter. 1986. $\mathrm{pH}$-induced physico-chemical changes of casein micelles in milk and their effect on renneting. 1. Effect of acidification on physicochemical properties. Neth. Milk Dairy J. 40:281-296.

Visser, S., C. J. Slangen, and P. J. Van Rooijen. 1987. Peptide substrates for chymosin (rennin). Biochem. J. 244:553-558.

Waungana, A., H. Singh, and R. J. Bennett. 1997. Influence of denaturation and aggregation of $\beta$-lactoglobulin on rennet coagulation properties of skim milk and ultrafiltered milk. Food Res. Int. 29:715-721.

Waungana, A., H. Singh, and R. J. Bennett. 1999. Rennet coagulation properties of skim milk concentrated by ultrafiltration: Effects of heat treatment and pH adjustment. Food Res. Int. 31:645-651.

Weitz, D. A., J. X. Zhu, D. J. Durian, H. Gang, and D. J. Pine. 1993. Diffusing-wave spectroscopy: The technique and some applications. Phys. Scr. T 49B:610-621.

Zhao, Z., and M. Corredig. 2014. Changes in the physico-chemical properties of casein micelles in the presence of sodium chloride in untreated and concentrated milk protein. Dairy Sci. Technol. 95:87-99. 